\title{
Preparation of ordered large pore SBA-15 silica functionalized with aminopropyl groups through one-pot synthesis $\dagger$
}

\author{
Xueguang Wang, Kyle S. K. Lin, Jerry C. C. Chan and Soofin Cheng* \\ Department of Chemistry, National Taiwan University, Taipei 106, Taiwan. \\ E-mail: chem1031@ntu.edu.tw; Fax:+886-2-23636359
}

Received (in Cambridge, UK) 28th May 2004, Accepted 1st September 2004

First published as an Advance Article on the web 8th October 2004

Highly ordered large pore SBA-15 silica functionalized with up to $16 \%$ aminopropyl groups, which gave high catalytic activity and selectivity toward flavanone synthesis through aldol condensation and subsequent intramolecular Michael addition of benzaldehyde and 2 '-hydroxyacetophenone, was synthesized for the first time via co-condensation of tetraethylorthosilicate (TEOS) and 3-aminopropyltriethoxysilane (APTES) using an amphiphilic block copolymer as the structure-directing agent.

The SBA-15 mesoporous silica of hexagonal-ordered pore structure, synthesized using amphiphilic triblock copolymers as the pore-directing agents and under acidic conditions, ${ }^{1}$ has received great attention in recent years because of its relatively large pore diameter and high hydrothermal stability in comparison to MCM41, its analog in the M41S family discovered by Mobil in $1992 .{ }^{2}$ In the past few years, organic-functionalized mesoporous silica materials have been extensively studied because a variety of functionality could be incorporated. Mesoporous silica functionalized with amino groups has been found to be effective in basecatalyzed reactions ${ }^{3}$ and useful as the intermediate for further functionalization. ${ }^{4}$ However, most of the related work was reported on MCM-type and HMS-type $^{6}$ materials of relatively small mesopores, which were synthesized under basic or neutral conditions. As to the SBA-15 system of large pores, because the protonated amino groups would interfere the self-assembly of the silica and the surfactant, to the best of our knowledge, only disordered materials were obtained by co-condensation of TEOS and an aminosilane, such as APTES, under the acidic synthesis environment. ${ }^{7,8}$ Here, we develop a one-pot method to synthesize highly ordered aminopropyl-functionalized mesoporous SBA-15 silica with high surface area and narrow pore-size distribution under strong acidic conditions. Moreover, the obtained material showed high efficiency in base-catalyzed reactions.

In the typical synthesis, TEOS was introduced to an aqueous $\mathrm{HCl}$ solution containing triblock copolymer Pluronic P123 $\left(\mathrm{EO}_{20} \mathrm{PO}_{70} \mathrm{EO}_{20}\right)$ and hydrolyzed for $1 \mathrm{~h}$ under stirring at $40{ }^{\circ} \mathrm{C}$. Then APTES was added into the mixture slowly. The molar composition of the mixture was $(1-x)$ TEOS : $x$ APTES : $0.017 \mathrm{P} 123: 6.1 \mathrm{HCl}: 169.4 \mathrm{H}_{2} \mathrm{O}$, where $x=0.1,0.15$ and 0.2 . The resultant mixture was stirred at $40{ }^{\circ} \mathrm{C}$ for $20 \mathrm{~h}$, followed by aging at $90{ }^{\circ} \mathrm{C}$ for $24 \mathrm{~h}$ under static conditions. The solid product was recovered by filtration and dried at room temperature overnight. The template was removed from the as-synthesized material by refluxing in ethanol for $24 \mathrm{~h}$. Finally, the material was filtered, washed several times with water and ethanol, and dried at $50{ }^{\circ} \mathrm{C}$.

The small-angle XRD patterns of the solvent-extracted materials with $10-20 \mathrm{~mol} \%$ amino groups in the initial mixture and synthesized through the TEOS pre-hydrolysis process were compared with that of the material containing $10 \mathrm{~mol} \%$ amino groups but synthesized without TEOS pre-hydrolysis (Fig. 1). The latter product is an X-ray amorphous material, while those with

$\uparrow$ Electronic supplementary information (ESI) available: pore-size distributions, TEM, ${ }^{29} \mathrm{Si}\left\{{ }^{1} \mathrm{H}\right\}$ CPMAS NMR spectra, TGA and the results of the Knoevenagel reaction of carbonyl compounds with cyanoacetate. See http://www.rsc.org/suppdata/cc/b4/b408022j/
TEOS pre-hydrolysis show one very intense peak and two weak peaks indexed to (100), (110), and (200) or (210) reflections, respectively, indicating that significant improvement of long range ordering of the hexagonal arrayed pore structure could be achieved by pre-hydrolysis of TEOS before the introduction of APTES. The peak intensity of the samples weakens as the amino loading increases, implying that the aminopropyl groups still have some interference on the assembly of the mesophase. Nevertheless, the TEM micrographs (ESI $\dagger$ ) indicated that all the samples prepared through TEOS pre-hydrolysis contained a well-hexagonallyarranged, one-dimensional pore structure, similar to that of pure siliceous SBA-15.

${ }^{29} \mathrm{Si}$ MAS NMR spectra (Fig. 2a) of the extracted materials functionalized with amino groups showed three resonance peaks up-field corresponding to $\mathrm{Q}^{4}(\delta=-111 \mathrm{ppm}), \mathrm{Q}^{3}(\delta=-101 \mathrm{ppm})$ and $\mathrm{Q}^{2}(\delta=-92 \mathrm{ppm})$, and two peaks down-field, assigned to $\mathrm{T}^{3}$ $(\delta=-67 \mathrm{ppm})$ and $\mathrm{T}^{2}(\delta=-58 \mathrm{ppm})$, respectively, ${ }^{7,9}$ where $\mathrm{Q}^{n}=\mathrm{Si}(\mathrm{OSi})_{4-n}(\mathrm{OH})_{n}, n=2-4$ and $\mathrm{T}^{m}=\mathrm{RSi}(\mathrm{OSi})_{3-m}(\mathrm{OH})_{m}$, $m=1-3$. The resolution and the intensity of the $\mathrm{T}$ and $\mathrm{Q}^{3}, \mathrm{Q}^{2}$

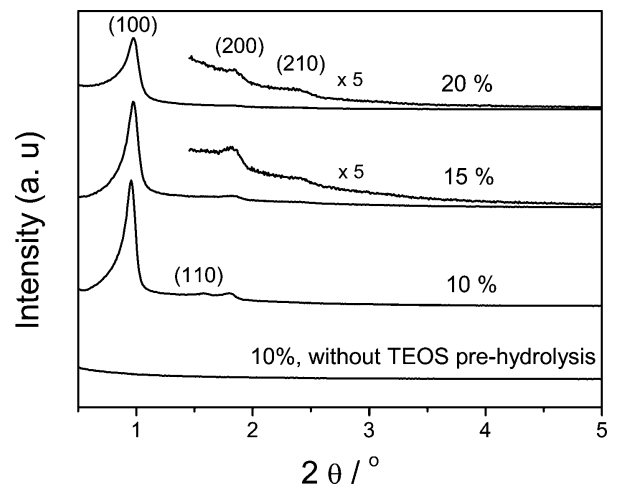

Fig. 1 XRD patterns of the extracted SBA-15 materials with different amounts of APTES in the synthesis mixtures and that synthesized with $10 \%$ APTES without TEOS pre-hydrolysis.

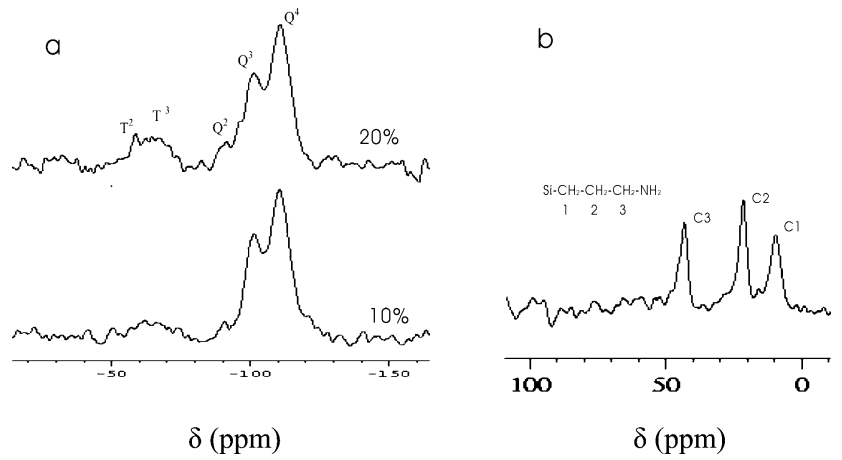

Fig. 2 (a) ${ }^{29}$ Si MAS NMR spectra of the extracted functionalized SBA-15 with different amounts of aminopropyl groups, and $(b){ }^{13} \mathrm{C}\left\{{ }^{1} \mathrm{H}\right\}$ CPMAS NMR spectrum of the extracted functionalized SBA-15 with $10 \%$ aminopropyl groups. 
Table 1 Physico-chemical properties of the extracted SBA-15 materials functionalized with various amount of aminopropyl groups

\begin{tabular}{|c|c|c|c|c|c|c|c|c|}
\hline Sample & $\begin{array}{l}\text { Cell } \\
\text { parameter/nm }\end{array}$ & $\Phi_{\mathrm{P}}^{a} / \mathrm{nm}$ & $\mathrm{PSD} / \mathrm{nm}$ & $S_{\mathrm{BET}} / \mathrm{m}^{2} \mathrm{~g}^{-1}$ & $\begin{array}{l}\text { Micropore } \\
\mathrm{SA} / \mathrm{m}^{2} \mathrm{~g}^{-1}\end{array}$ & Pore vol. $/ \mathrm{cm}^{3} \mathrm{~g}^{-1}$ & $W_{\mathrm{t}} / \mathrm{nm}$ & $\begin{array}{l}\mathrm{N} \text { content }^{b} \\
\text { (theor. value) } / \mathrm{mmol} \mathrm{g}^{-1}\end{array}$ \\
\hline SBA-15 & 10.8 & 7.8 & 0.76 & 769 & 48 & 1.04 & 3.0 & 一 \\
\hline SBA- $15 \% \mathrm{NH}_{2}$ & 10.5 & 5.9 & 0.83 & 443 & 22 & 0.53 & 4.6 & $1.85(2.22)$ \\
\hline SBA- $20 \% \mathrm{NH}_{2}$ & 10.5 & 5.7 & 0.94 & 290 & 16 & 0.38 & 4.8 & $2.28(2.86)$ \\
\hline
\end{tabular}

${ }^{a} \mathrm{BJH}$ pore diameter calculated from the adsorption branch. ${ }^{b}$ Estimated by elemental analysis.

peaks could be greatly increased by using a cross-polarization technique through ${ }^{1} \mathrm{H} . \dagger$ The presence of $\mathrm{T}$ peaks confirms the incorporation of the aminosilane moieties as a part of the silica wall structure. The ${ }^{13} \mathrm{C}\left\{{ }^{1} \mathrm{H}\right\}$ CPMAS NMR spectrum (Fig. 2b) of the extracted sample with $10 \%$ amino groups clearly displayed three peaks, at 10,21 and $42 \mathrm{ppm}$, corresponding to the $\mathrm{C}$ atoms on the $\mathrm{Si}-\mathrm{CH}_{2}-\mathrm{CH}_{2}-\mathrm{CH}_{2}-\mathrm{NH}_{2}$ chain in sequence from left to right. ${ }^{8,10}$ These results show that the aminopropyl groups were not decomposed during the synthesis procedure. In addition, no resonance peaks corresponding to the surfactant $\mathrm{P} 123$ were observed in the range of $67-77 \mathrm{ppm}$, indicating that the surfactant was completely removed during the extraction. ${ }^{11}$ This result was also supported by the TG analysis. $\dagger$

Table 1 shows the physico-chemical properties of the extracted materials. The cell parameters calculated from the $d$-spacings of the (100) reflection peaks only slightly changed with the amino loadings. Based on the elemental analysis, the contents of amino groups in the samples are proportional to the amount of APTES added in the starting mixture. However, the $\mathrm{N}$ contents were about $80 \%$ of the theoretical ones, indicating that APTES was more difficult than TEOS to hydrolyze and condense into the silica framework. The elemental analysis results are also in reasonable agreement with the $\mathrm{T}^{m} / \mathrm{Q}^{n}$ area ratios of the ${ }^{29} \mathrm{Si}$ MAS NMR spectra.

$\mathrm{N}_{2}$ adsorption-desorption isotherms of the extracted products with 10-20\% amino groups exhibit the characteristic type IV isotherms with steep increases in adsorption at $P / P_{0}=0.5-0.75$, due to capillary condensation of nitrogen in the mesopores. The $\mathrm{BJH}$ pore-size distribution (PSD) analysis shows very narrow PSD values in the diameter range of 5.7-7.8 $\mathrm{nm}$. As can be seen in Table 1, the pore diameter, BET surface area, micropore surface area and pore volume decrease with the increase in amino loadings. In contrast, the wall thickness $\left(W_{\mathrm{t}}\right)$ increases from 3.0 to $3.9 \mathrm{~nm}$ when $10 \%$ aminopropyl groups were incorporated, and that it is further increased and remains around 4.6-4.8 nm when more than $15 \%$ aminopropyl groups were incorporated.

The extracted SBA-15 with $10 \%$ amino groups was tested as a base catalyst in the liquid phase condensation of benzaldehyde (A) and 2'-hydroxyacetophenone (B) to form 2'-hydroxychalcone (C) and flavanone (D) at $140{ }^{\circ} \mathrm{C}$. Flavanone is an important intermediate in many pharmaceutical syntheses and members of the flavanoid family were documented to have various pharmacological activities. ${ }^{12}$ Before the catalytic reaction, the mesoporous material was treated with a methanol solution of $0.2 \mathrm{M}$ tetramethylammonium hydroxide to neutralize the protonated amino groups. The solid was recovered by filtration, washed with methanol, and finally dried at $120{ }^{\circ} \mathrm{C}$ for one day. Various organic solvents and solvent-free conditions were examined. Table 2 shows that the amino-functionalized SBA-15 has a very high catalytic activity and selectivity to flavanone when no solvent is used. When the $\mathbf{A} / \mathbf{B}$ molar ratio was increased from 1 to 1.5 , the conversion of B increased from 84 to $91.9 \%$ and the selectivity to $\mathbf{D}$ was retained at around $70 \%$. From GC-MS analysis, no products other than $\mathbf{C}$ and $\mathbf{D}$ were formed in the reaction. When the used catalyst was reused after it was washed with methanol and dried at $120{ }^{\circ} \mathrm{C}$, a slightly lower conversion of B (81 versus $92 \%)$ and similar selectivity to $\mathbf{D}$ were observed (Table 2). The decrease in conversion is probably due to the incomplete removal of absorbed species from the active sites by methanol. On the other hand, the same reaction using pure siliceous SBA-15, which was pre-treated with a methanol solution of $0.2 \mathrm{M}$ tetramethylammonium hydroxide, as
Table 2 Reaction of benzaldehyde and 2'-hydroxyacetonphenone over $0.15 \mathrm{~g}$ extracted $10 \%$ aminopropyl SBA- 15 at $140{ }^{\circ} \mathrm{C}$ for $8 \mathrm{~h}^{a}$

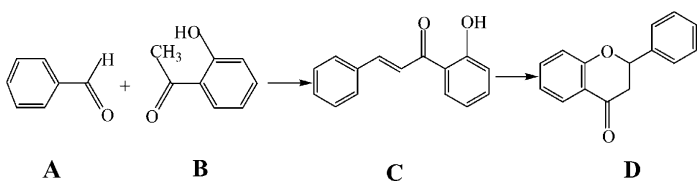

\begin{tabular}{lllll}
\hline Reaction & $\begin{array}{l}\text { A/B } \\
\text { (molar ratio) }\end{array}$ & $\begin{array}{l}\text { Conversion } \\
\text { of B }(\%)\end{array}$ & $\begin{array}{l}\text { Selectivity } \\
\text { to D }(\%)\end{array}$ \\
\hline 1 & 1 & Dimethyl sulfoxide & 52 & 68 \\
2 & 1 & Benzonitrile & 35 & 48 \\
3 & 1 & Nitrobenzene & 52 & 39 \\
4 & 1 & $c-$ & 84 & 71 \\
5 & 1.5 & $c-$ & 92 & 69 \\
6 & 1.5 & $d-$ & 81 & 68
\end{tabular}

${ }^{a}$ Reaction products were identified by GC-MS. Products in Reactions $1-3$ were analyzed by GC, using n-dodecane as internal standard. Products in Reactions 4-6 were diluted with dimethyl sulfoxide, followed by GC analysis. Reaction conditions: $10 \mathrm{mmol}$ A, 10 or $15 \mathrm{mmol} \mathrm{B.}{ }^{b} 5 \mathrm{~mL}$ solvent. ${ }^{c}$ Without solvent. ${ }^{d}$ Re-use of the catalyst without solvent.

the catalyst a gave very low conversion $(3.1 \%)$ of $\mathbf{B}$ and $68 \%$ selectivity to $\mathbf{D}$. These results confirm that the catalytic active sites in amino-functionalized SBA-15 are the aminopropyl groups instead of surface $\mathrm{Si}^{-} \mathrm{O}^{-}$groups. Besides, the amino-functionalized SBA-15 also showed an excellent performance in Knoevenagel condensation. In the condensation reaction of benzenaldehyde $(10 \mathrm{mmol})$ and ethyl cyanoacetate $(10 \mathrm{mmol})$ in cyclohexane $(10 \mathrm{~mL})$, the yield of 2-cyano-3-phenyl-acrylic acid ethyl ester was in excess of $99 \%$ at $82{ }^{\circ} \mathrm{C}$ after $1 \mathrm{~h} . \dagger$

This project was supported by the National Science Council, Taiwan.

\section{Notes and references}

1 D. Zhao, J. Feng, Q. Huo, N. Melosh, G. H. Frederichson, B. F. Chmelka and G. D. Stucky, Science, 1998, 279, 548.

2 C. T. Kresge, M. E. Leonowicz, W. J. Roth, J. C. Vartuli and J. S. Beck, Nature, 1992, 359, 710.

3 D. J. Macquarrie and D. B. Jackson, Chem. Commun., 1997, 1781.

4 K. A. Utting and D. J. Macquarrie, New J. Chem., 2000, 24, 591; D. Brunel, F. Fajula, J. B. Nagy, B. Deroide, M. J. Verhoef, L. Veum, J. A. Peters and H. Van Bekkum, Appl. Catal., A: General, 2001, 213, 73. 5 T. Yokoi, H. Yoshitake and T. Tatsumi, J. Mater. Chem., 2004, 14, 951.

6 D. J. Macquarrie, D. B. Jackson, J. E. G. Mdoe and J. H. Clark, New J. Chem., 1999, 23, 539 .

7 A. S. M. Chong and X. S. Zhao, J. Phys. Chem. B, 2003, 107, 12650

8 H. H. P. Yiu, P. A. Wright and N. P. Botting, J. Mol. Catal. B: Enzym., 2001, 15, 81 .

9 F. Juan and E. Ruiz-Hitzky, Adv. Mater., 2000, 12, 430; A. M. Liu, K. Hidajat, S. Kawi and D. Y. Zhao, Chem. Commun., 2000, 1145.

10 N. Liu, R. A. Assink, B. Smarsly and C. J. Brinker, Chem. Commun., 2003, 1146.

11 C. Yang, B. Zibrowius and F. Schüth, Chem. Commun., 2003, 1772.

12 S. Makela, M. Poutanen, M. L. Kostian, N. Lehtimaki, L. Strauss, R. Santti and R. Vihko, Proc. Soc. Exp. Biol. Med., 1998, 217, 310. 